University of South Carolina

Scholar Commons

2003

\title{
Development of a Novel Electrochemical Method to Deposit High Corrosion Resistant Silicate Layers on Metal Substrates
}

\author{
Basker Veeraraghavan \\ University of South Carolina - Columbia \\ Bala Haran \\ University of South Carolina - Columbia \\ Dragan Slavkov \\ University of South Carolina - Columbia \\ Swaminatha Prabhu \\ University of South Carolina - Columbia \\ Branko N. Popov \\ University of South Carolina - Columbia, popov@engr.sc.edu \\ Follow this and additional works at: https://scholarcommons.sc.edu/eche_facpub \\ ¿rant parthe for additional authors commons
}

\section{Publication Info}

Electrochemical and Solid-State Letters, 2003, pages B4-B8.

(c) The Electrochemical Society, Inc. 2003. All rights reserved. Except as provided under U.S. copyright law, this work may not be reproduced, resold, distributed, or modified without the express permission of The Electrochemical Society (ECS). The archival version of this work was published in Electrochemical and Solid-State Letters.

http://www.electrochem.org/

Publisher's link: http://dx.doi.org/10.1149/1.1537092

DOI: 10.1149/1.1537092

This Article is brought to you by the Chemical Engineering, Department of at Scholar Commons. It has been accepted for inclusion in Faculty Publications by an authorized administrator of Scholar Commons. For more information, please contact digres@mailbox.sc.edu. 


\section{Author(s)}

Basker Veeraraghavan, Bala Haran, Dragan Slavkov, Swaminatha Prabhu, Branko N. Popov, and Bob Heimann 


\title{
Development of a Novel Electrochemical Method to Deposit High Corrosion Resistant Silicate Layers on Metal Substrates
}

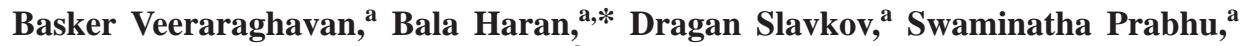 \\ Branko Popov, ${ }^{\mathrm{a}, *, \mathrm{z}}$ and Bob Heimann ${ }^{\mathrm{b}}$ \\ ${ }^{a}$ Center for Electrochemical Engineering, Department of Chemical Engineering, University of South \\ Carolina, Columbia, South Carolina 29208, USA \\ ${ }^{b}$ Elisha Technologies Company LLC, Moberly, Missouri 65270, USA
}

\begin{abstract}
A novel method for electrodepositing silicates on metallic substrates from aqueous solutions has been developed. The technique is demonstrated by forming a passive film on galvanized steel. The silicate layer was deposited cathodically from a bath containing PQ Corporation N sodium silicate solution (3.22 weight ratio sodium silicate, $37.5 \%$ solution in water). A post-treatment drying process increased the $\mathrm{Si}$ content in the coating and improved the corrosion characteristics of the silicate layer. Deposition parameters like bath concentration and temperature have been optimized using corrosion characteristics and surface morphology of the final coating. Finally, stability studies show that the silicate coatings obtained using this method have higher barrier resistance and better stability as compared to chrome passivates. The technique developed here shows promise as an alternative to chrome passivation for corrosion protection of metals.

(c) 2003 The Electrochemical Society. [DOI: 10.1149/1.1537092] All rights reserved.
\end{abstract}

Manuscript submitted September 4, 2002; revised manuscript received October 31, 2002. Available electronically January 3, 2003.

Silicadizing is a process that has been explored to protect the surface of metals from corrosion. However, the formation of silica coatings for preventing corrosion on steel surfaces remains a challenge and is being actively explored. Deposition of silica films has been accomplished previously by several methods including sol-gel deposition, ${ }^{1}$ precipitation, ${ }^{2}$ or through anodic deposition ${ }^{3}$ at high voltages. Cheng et al. ${ }^{1}$ report the development of an aluminosilicate coating through a sol-gel process in an autoclave at $175^{\circ} \mathrm{C}$. While the deposit yields superior corrosion characteristics as compared to $\mathrm{Cr}$ conversion coatings, the entire synthesis procedure is laborious, time consuming, and is not suited for commercial applications. Apart from this method, Jesionowski ${ }^{2}$ has prepared colloidal silica by precipitation from sodium silicate solution using sulfuric acid in emulsion medium. Speers and $\mathrm{Cahoon}^{3}$ report the deposition of $\mathrm{Si}$ from alkaline silicate electrolytes by anodizing $\mathrm{Al}$ at $350 \mathrm{~V}$. However, this process is limited to $\mathrm{Al}$ (or similar metals which have stable anodic oxide films) and also involves application of large potentials. Recently, Chigane et al. ${ }^{4}$ reported formation of silica thin films on copper substrates through cathodic electrolysis of $\mathrm{pH} 3.3$ ammonium hexafluorosilicate solution. In acid solutions, fluoride ions help keep the silica stable in solution. In the absence of fluoride ions, the bath becomes unstable and precipitates as $\mathrm{Si}(\mathrm{OH})_{4}$. However, high $\mathrm{pH}$ and presence of fluoride ions limits the process developed by Chigane et al. ${ }^{4}$ to metals capable of withstanding corrosive environments. Further, the deposits obtained by them were highly porous and hence not suitable as a protective coating.

In this paper, we report on a novel method to synthesize silicates from sodium silicate solution by electrolysis. The process described here is general in nature and can be applied for a wide range of metals. Further, it is inexpensive and the entire process is environmentally friendly. We focus on applying a silicate coating to galvanized steel. The corrosion characteristics of the deposit have been studied as a function of bath parameters. The bath properties and the post-treatment conditions have been optimized for obtaining a stable deposit with uniform layers of $\mathrm{SiO}_{2}$ on the zinc surface.

The $\mathrm{N}$ sodium silicate solution (PQ Corporation, $37.5 \mathrm{wt} \%$ silicic acid, sodium salt in $62.5 \mathrm{wt} \%$ water) with a $\mathrm{SiO}_{2}: \mathrm{Na}_{2} \mathrm{O}$ molar ratio of 3.22 was used as the silicate precursor. The amount of monomeric and polymeric silica in the bath was analyzed by a Beckman DIP520 colorimeter using the molybdate method. The silicate deposition was carried out in a two-electrode plating cell made of

\footnotetext{
* Electrochemical Society Active Member

${ }^{\mathrm{z}}$ E-mail: popov@engr.sc.edu
}

glass with Pt-niobium anodes. Zinc plated steel panels (EZG-60G) of surface area $116 \mathrm{~cm}^{2}$ each side, as-received from ACT labs were used as the cathodes. Zinc was coated onto the steel substrate using electrodeposition at a current density of $30 \mathrm{~mA} / \mathrm{cm}^{2}$ at room temperature from an acidic bath $(\mathrm{pH} 4)$ containing $300 \mathrm{~g} / \mathrm{L} \mathrm{ZnSO}_{4}, 30$ $\mathrm{g} / \mathrm{L} \mathrm{ZnCl}{ }_{2}$, and $30 \mathrm{~g} / \mathrm{L} \mathrm{H}_{3} \mathrm{BO}_{3}$. Prior to silica deposition, the panels were degreased with acetone and washed with demineralized water. The experimental study composed of optimizing the deposition parameters such as concentration of sodium silicate solution in the electrolyte, bath temperature, applied potential, time of deposition, and the post-treatment temperature.

The corrosion characteristics of all the panels were tested in 0.5 $\mathrm{M} \mathrm{Na}_{2} \mathrm{SO}_{4}$ solution at $\mathrm{pH}$ 4. A three-electrode setup was used to study the corrosion behavior of the mineralized samples. Pt was used as the counter electrode. After the potential stabilized, nondestructive evaluation of the surface was done using linear polarization. During linear polarization, the potential was varied $10 \mathrm{mV}$ above and below the open-circuit potential at a scan rate of 0.1667 $\mathrm{mV} / \mathrm{s}$.

Separately, scanning electron microscope (SEM), thermogravimetric analysis, and energy dispersive analysis with X-rays (EDAX) were done for checking the morphology and the composition of the coatings, respectively. Surface images of bare and mineralized galvanized panels were obtained with a Hitachi S-2500 Delta SEM. Constitutive elements on the surface of the panels were analyzed using EDAX. X-ray photoelectron spectroscope analysis were obtained using a HP 5950A spectrometer which is capable of generating monochromator $\mathrm{X}$-rays at a background pressure of $5 \times 10^{-9}$ Torr. Calibration of the analyzer was performed using gold and graphite, and the accuracy of the analyzer for detecting binding energy is within $\pm 0.05 \mathrm{eV}$. After calibration, the depth profile of the coating was analyzed by sputtering it with the X-ray and the structure of the coating was determined. This procedure has been described in detail elsewhere ${ }^{5}$ and is used in many silicate related fields. ${ }^{6}$ The particle size of the deposits was checked using contact atomic force microscope (AFM) analysis. The surface area of the deposits was determined using a chemisorption Brunauer-EmmettTeller (BET) analyzer.

Initially, a layer of silicate coating was formed on galvanized steel in 3.22 N PQ solution diluted eight times with water (5.6 wt \% sodium silicate in water). The zinc plated panels were electrolyzed cathodically in this bath $\left(\mathrm{pH} \mathrm{10.5)}\right.$ at $12 \mathrm{~V}$ for $15 \mathrm{~min}$ at $75^{\circ} \mathrm{C}$. Subsequent to deposition, the panel was washed and the corrosion 


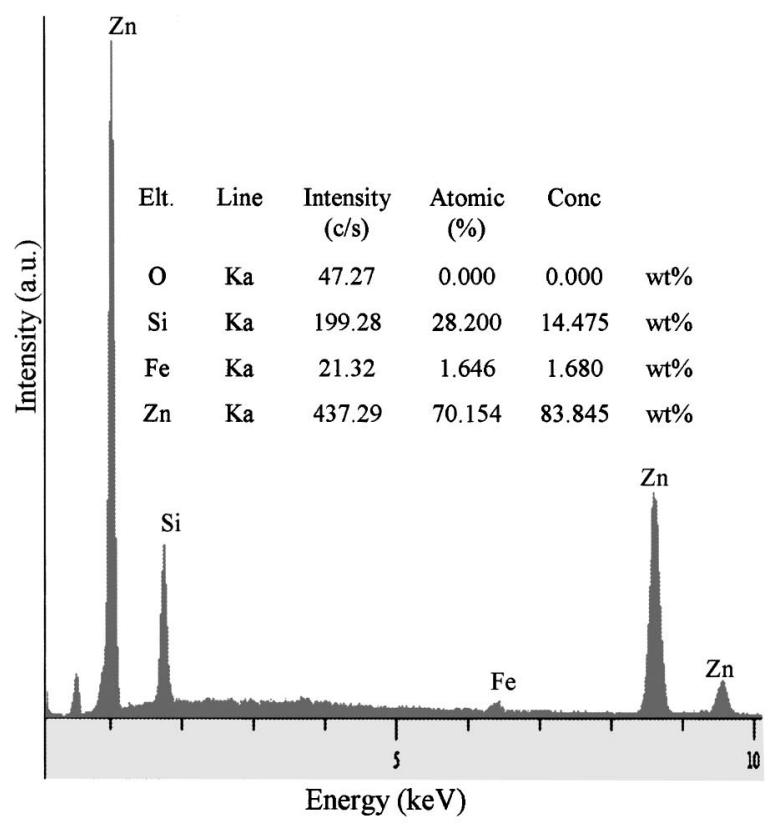

a) Electrodeposited at $12 \mathrm{~V}$

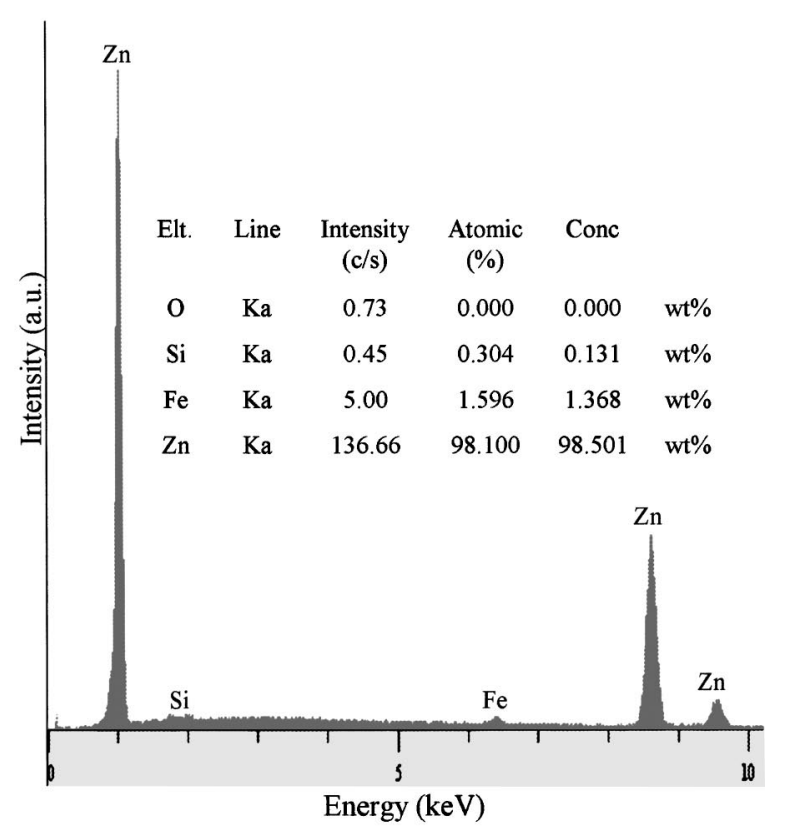

b) No current

Figure 1. Effect of electrolysis on the composition of the coatings prepared in a 1:8 PQ bath at $75^{\circ} \mathrm{C}$ by EDAX analysis.

resistance was measured in $0.5 \mathrm{M} \mathrm{Na}_{2} \mathrm{SO}_{4}$ solution. The bare galvanized steel has a corrosion resistance of $250 \Omega \mathrm{cm}^{2}$. The silicatecoated sample has a resistance of $1400 \Omega \mathrm{cm}^{2}$, which is comparable to values reported for chromate conversion coatings in literature. ${ }^{7}$ The results are highly reproducible and the mineral layer gives five times higher resistance than did the untreated zinc surface. Figure 1 presents a comparison of the surface composition of samples prepared with and without applied potential. Significant amount of Si is seen on the surface for samples subjected to electrolysis (Fig. 1a). Galvanized steel samples, kept under similar conditions as in Fig. 1a but not subjected to potentiostatic electrolysis at $12 \mathrm{~V}$, do not show any presence of Si on the surface (Fig. 1b). These results show that $\mathrm{Si}$ is formed on the surface of $\mathrm{Zn}$ under an applied potential. X-ray

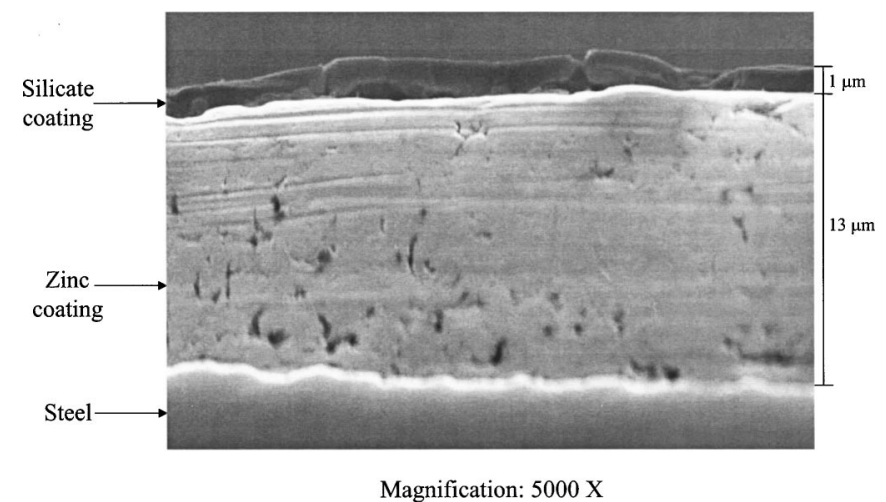

Figure 2. Cross-sectional SEM picture of sample prepared by electrolysis in a $1: 8 \mathrm{PQ}$ bath at $75^{\circ} \mathrm{C}$

photon spectroscopy (XPS) shows that there is a thin zinc silicate layer on top of the zinc substrate followed by a layer of $\mathrm{SiO}_{2}$ and $\mathrm{Si}_{2} \mathrm{O}_{7}$.

Apart from applied potential, another precondition for forming a silicate layer is the heating of the bath. This was confirmed by the negligible amount of silicate $(1.4 \mathrm{wt} \%)$ formed on samples electrolyzed at room temperature. A bath temperature of $75^{\circ} \mathrm{C}$ increases the amount of silicates $(14.5 \mathrm{wt} \%)$ on the surface. However, further increase in the bath temperature to $85^{\circ} \mathrm{C}$ does not lead to any significant increase in Si content (15.8 wt \%). Also, the final deposits obtained were found to be highly porous in nature with significant cracks. Hence, our next set of studies was aimed at increasing the corrosion resistance by forming a more uniform film of Si on the surface. In order to accomplish this it was essential to understand the deposition of $\mathrm{Si}$ on $\mathrm{Zn}$. As mentioned in the introduction, Si deposition from an aqueous bath with water as the solvent is thermodynamically not feasible due to the small potential window of stability of water. Under an applied potential, before Si anions can be electrochemically reduced on the surface of $\mathrm{Zn}$, all the solvent (water) will be electrolyzed. The soluble silicate is a complex mixture of silicate anions. ${ }^{8}$ Hence it can be expected that under large applied electric fields, the negatively charged silicate species migrate to the anode and are deposited. Speers and Cahoon ${ }^{2}$ report that the thickness of the silicate layer formed using such method is limited only by the time of anodic deposition. They report thickness up to 100 $\mu \mathrm{m}$ for 20 min of deposition. A cross-sectional SEM analysis of the silicate coating obtained using our cathodic process can be seen in Fig. 2. Note that the silicate layer is not more than $1 \mu \mathrm{m}$ thick. Unlike anodic silicate deposition, ${ }^{2}$ the deposits are very thin (1-3 $\mu \mathrm{m})$. The maximum thickness seems to be limited to $3 \mu \mathrm{m}$. These results indicate that the mechanism of cathodic Si deposition in our case is more complex than was previously reported. ${ }^{2}$ Pourbaix $^{9}$ diagrams show that $\mathrm{Zn}$ cannot exist as $\mathrm{Zn}^{2+}$ ions at $\mathrm{pH} 10.5$ and will be present as bizincate $\left[\mathrm{ZnO}(\mathrm{OH})^{-}\right]$ions. According to Bass and Turner, ${ }^{8}$ the PQ solution contains mainly $Q_{3}$ and $Q_{4}$-type silica, where $Q_{\mathrm{i}}$ notation indicates the number of silicon atoms linked through intermediate oxygen atoms to the $\mathrm{Si}$ atom in focus. In our studies, quantitative analysis of monomeric and polymeric silica was done by colorimetry using the molybdate method. The monomeric silica reacts with the molybdate anion to form a yellow silicomolybdate $(410 \mathrm{~nm})$ solution. The polymeric silica breaks to monomeric silica slowly in dilute acidic media. The amount of silicomolybdate determined by colorimetry translates directly to the amount of monomeric and polymeric silica in the solution. From our colorimetric studies, we found that the total silica in the 1:8 PQ bath comprises of $25 \%$ monomeric silica and $75 \%$ polymeric silica. An equilibrium exists between $\mathrm{SiO}_{2}$ and silica monomer according to the equation

$$
\mathrm{SiO}_{2}+2 \mathrm{H}_{2} \mathrm{O} \rightarrow \mathrm{Si}(\mathrm{OH})_{4}
$$


Table I. Comparison of resistances of samples dried at $100^{\circ} \mathrm{C}$ and at room temperature for $1 \mathrm{~h}$ as a function of concentration of PQ bath.

\begin{tabular}{lcc} 
& \multicolumn{2}{c}{ Average resistance $\left(\Omega \mathrm{cm}^{2}\right)$} \\
\cline { 2 - 3 } $\begin{array}{l}\text { PQ bath } \\
\text { concentration }\end{array}$ & $\begin{array}{c}\text { Room temp } \\
\text { dried }\end{array}$ & $100^{\circ} \mathrm{C}$ dry, $1 \mathrm{~h}$ \\
\hline $1: 8$ & 1655 & 8147.9 \\
$1: 4$ & 1900 & $1 \times 10^{4}$ \\
$1: 3$ & 2116.2 & $5 \times 10^{5}$ \\
$1: 2$ & 2612 & $6 \times 10^{5}$ \\
$1: 1$ & 2850 & $7 \times 10^{5}$
\end{tabular}

The monomeric silicate (of the $Q_{0}$ type) polymerizes according to the equation

$$
n \mathrm{Si}(\mathrm{OH})_{4} \rightarrow \mathrm{Si}_{n} \mathrm{O}_{(4 n-n x / 2)}(\mathrm{OH})_{n x}+\frac{4 n-n x}{2} \mathrm{H}_{2} \mathrm{O}
$$

The polymeric silicates (of the $Q_{3}$ and $Q_{4}$ type) can polymerize according to the equation below

$$
\begin{aligned}
\mathrm{Si}_{n} \mathrm{O}_{(4 n-n x / 2)}(\mathrm{OH})_{n x}+z \mathrm{OH}^{-} \rightarrow & \mathrm{Si}_{n} \mathrm{O}_{(4 n-n x / 2)}(\mathrm{OH})_{n x-z} \mathrm{O}_{z}^{z-} \\
& +z \mathrm{H}_{2} \mathrm{O}
\end{aligned}
$$

According to Iler, ${ }^{10} \mathrm{Si}(\mathrm{OH})_{4}$ condenses with any preexisting solid surface that bears $\mathrm{OH}$ groups with which it can react, namely, an $\mathrm{MOH}$ surface. In this case, zinc silicate will be formed according to the following equation

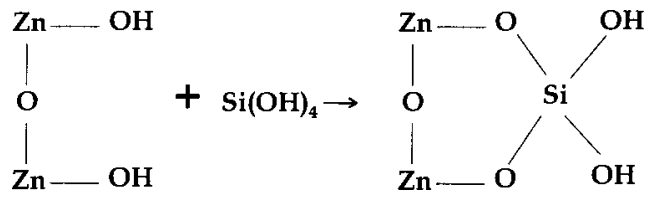

Application of an electric field to the PQ bath leads to the electrolysis of water. This results in generation of $\mathrm{OH}^{-}$ions at the cathode (substrate) according to the following equation

$$
\mathrm{H}_{2} \mathrm{O}+2 \mathrm{e}^{-} \rightarrow 2 \mathrm{OH}^{-}+\mathrm{H}_{2}
$$

The production of $\mathrm{OH}^{-}$ions will result in a shift of Reaction 3 to the right. This causes more amount of the silicate to be polymerized to a higher degree. Subsequent to polymerization, the silicate is deposited on the surface of zinc silicate layer. As seen from Eq. 5, electrolysis results in the hydrolysis of water, which in turn increases the $\mathrm{pH}$ close to the electrode surface and aids in the formation of silicates on the surface. Hence, the process proceeds in two stages: ( $i$ ) formation of zinc silicate according to Eq. 4, and ( $i i)$ formation of a surface layer of polymeric silicate due to condensa- tion of polymeric species formed by Eq. 2 and 3. Electrolysis results in increasing the $\mathrm{pH}$ near the electrode surface and hence, aids in the polymerization of silicates on the surface.

One approach to increasing the Si content on the surface would be to increase the number of polymeric silicate species in solution. To study this, deposition was done in five different concentration ratios of $3.22 \mathrm{~N}$ PQ solution (1:8, 1:4, 1:3, 1:2, and 1:1 v/v mix solutions of PQ solution:water). For example, $3 \mathrm{~L}$ of 1:3 PQ solution can be prepared by adding $750 \mathrm{~mL}$ of $3.22 \mathrm{~N}$ PQ solution to 2250 $\mathrm{mL}$ of water. The bath was maintained at a temperature of $75^{\circ} \mathrm{C}$ and the depositions were carried out at a potential of $12 \mathrm{~V}$. Also, Roggendorf et al. ${ }^{11}$ have reported that silicates dried from sodium silicate solutions between $40-60^{\circ} \mathrm{C}$ have a size range between 5 and $100 \mathrm{~nm}$, while those dried to $100^{\circ} \mathrm{C}$ exhibit a size of $1-5 \mathrm{~nm}$. These results indicate that drying the silicates plays an important role in determining their structural properties. Krysztafkiewicz et al. ${ }^{12}$ have identified that the surface of silicate-coated samples have a significant amount of loosely bound silicates that are hydrophilic in nature. Hence, rinsing the samples after deposition removes any loosely attached silicates from the surface. Heating will result in the condensation and densification of loosely attached silicates on the surface. To study the effect of drying, one set of samples was dried at room temperature for $24 \mathrm{~h}$ and another set at $100^{\circ} \mathrm{C}$ for $1 \mathrm{~h}$. The uniformity of the coatings was determined by testing corrosion resistance of the samples in $0.5 \mathrm{M} \mathrm{Na}_{2} \mathrm{SO}_{4}$ solution at various points. Table I shows the average corrosion resistances of samples obtained as a function of the concentration of the bath used. Note that samples that are not subjected to post-treatment heating have low corrosion resistances, and a change in concentration of the PQ bath has no effect on their corrosion resistances. EDAX analysis was used to check the surface Si content. The Si content for the samples prepared in a $1: 8$ bath and dried in air is $14 \mathrm{wt} \%$. Increasing the bath concentration from 1:8 to 1:3 does not lead to any appreciable increase in Si content. However, the surface Si concentration increases significantly when the samples are heated after deposition. The average $\mathrm{Si}$ content for a sample prepared in a 1:8 bath and heated at $100^{\circ} \mathrm{C}$ is around $24 \%$. However, samples prepared in a $1: 3$ bath and heated to $100^{\circ} \mathrm{C}$ have an average $\mathrm{Si}$ content of $64 \%$. As before, we see that this increase in Si concentration leads to a significant increase in corrosion resistance. This result can be seen from Table I, where the heated samples show increased corrosion resistance for all concentrations. For more dilute solutions than 1:3 mix, the average resistance is low. At a concentration ratio of $1: 3$ the average resistance of the sample increases to the order of $10^{5} \Omega \mathrm{cm}^{2}$. Further increase in concentration does not lead to significant increase in resistance. Hence, further studies were done at the optimized concentration ratio of 1:3. Also, all samples were subjected to a post-treatment heating procedure.

Next, the stability of the coatings were studied by immersing them in $\mathrm{pH} 40.5 \mathrm{M} \mathrm{Na}_{2} \mathrm{SO}_{4}$ solution continuously. The corrosion resistance decreases from $10^{5}$ to the order of $10^{3} \Omega \mathrm{cm}^{2}$ after a week. The primary factor causing this decrease in resistance in aqueous media is the porous nature of the silicate coating. SEM pictures of the freshly prepared sample (not shown here) show that cracks exist on the surface. These cracks facilitate the entry of the solution through the coating and attack the underlying substrate. The cracks

Table II. Comparison of corrosion resistance of samples mineralized in $1: 3 \mathrm{PQ}$ bath at $75^{\circ} \mathrm{C}$ at $12 \mathrm{~V}$ for 15 min and dried at different temperatures for $1 \mathrm{~h}$.

Average resistance

$$
\left(\Omega \mathrm{cm}^{2}\right)
$$

\begin{tabular}{lccccccc}
\cline { 2 - 6 } Day & $40^{\circ} \mathrm{C}$ & $75^{\circ} \mathrm{C}$ & $100^{\circ} \mathrm{C}$ & $125^{\circ} \mathrm{C}$ & $150^{\circ} \mathrm{C}$ & $175^{\circ} \mathrm{C}$ \\
\hline Initial & 3833.4 & $7 \times 10^{4}$ & $5 \times 10^{5}$ & $6 \times 10^{5}$ & $7 \times 10^{5}$ & $9 \times 10^{5}$ & $1 \times 10^{6}$ \\
1st day & 921.3 & 1538.3 & 2570.2 & 8211.7 & 9624.7 & 9066 \\
4th day & 500.4 & 822.8 & 846.8 & 3782 & 5010.8 & 12096 \\
7th day & 440.2 & 644.2 & 811.8 & 854.6 & 2271.1 & 4153.9
\end{tabular}



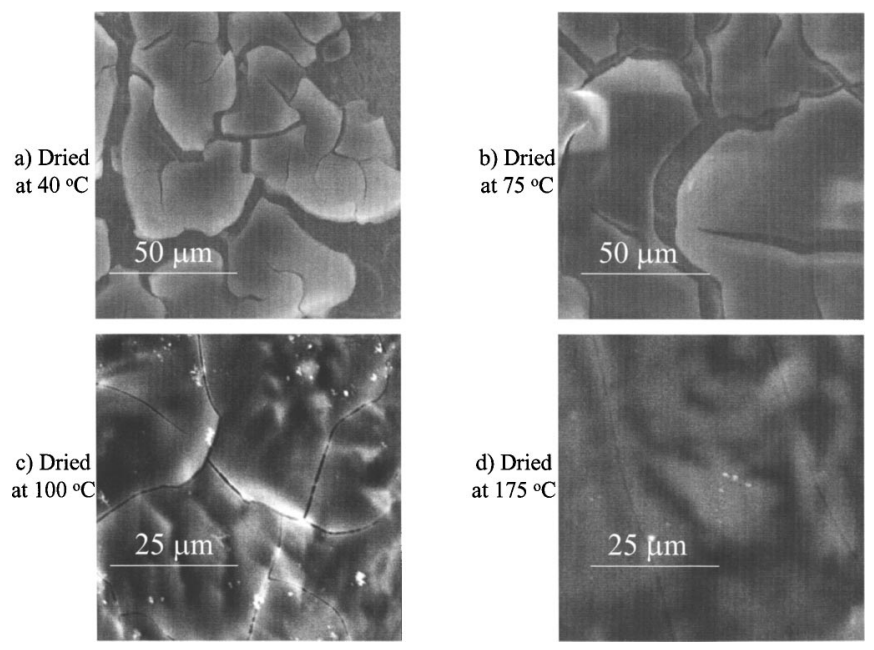

Figure 3. Variation in the surface crack structure as a function of drying temperature.

become large (from $0.5 \mu \mathrm{m}$ in the freshly prepared sample to $2 \mu \mathrm{m}$ in the corroded sample) due to the continued exposure to aqueous media. Also, appearance of small spongy white particles can be seen on the surface. These are the corrosion products of the underlying $\mathrm{Zn}$ metal. The SEM picture (not shown) also shows that the substrate covered with $\mathrm{SiO}_{2}$ does not have any corrosion products on its surface. Hence, it is clear that the stability of the coating can be improved by developing uniform layers of $\mathrm{SiO}_{2}$.

Since drying the samples causes significant increase in resistance, it is essential to optimize both the heating temperature and the heating time. Hence, samples were prepared using the optimized bath conditions and then subjected to drying at different temperatures. The heating time for these samples was held constant at $1 \mathrm{~h}$. The samples were then left under the corrosion solution to test their stability. The samples were tested for corrosion resistance periodically in $0.5 \mathrm{M} \mathrm{Na}_{2} \mathrm{SO}_{4}$ solution. Table II presents the average corrosion resistance for samples mineralized in 1:3 PQ solution and heated to different temperatures. Samples that were heated at temperatures $\leqslant 100^{\circ} \mathrm{C}$ show drastic decrease in corrosion resistance with continued exposure to water. However, for temperatures greater than $100^{\circ} \mathrm{C}$, the samples begin to show better corrosion stability. It can also be seen that heating samples at $175^{\circ} \mathrm{C}$ shows promise for stabilizing the surface coating and keeping the resistance high. The reason for this increased stability with heating temperature is due to the decrease in the size and number of cracks on the surface. Figure $3 a-d$ presents the SEM pictures for the samples heated at 40,75 , 100 , and $175^{\circ} \mathrm{C}$. The crack size decreases from $10 \mu \mathrm{m}$ in case of samples heated at $40^{\circ} \mathrm{C}$ (seen in Fig. 3a), to $0.25 \mu \mathrm{m}$ in the case of samples heated at $175^{\circ} \mathrm{C}$ (seen in Fig. 3d). The decrease in the crack opening (Fig. 3d) helps in decreasing the entry of water through them and hence the observed increase in stability. This result indicates that drying plays an important role in determining the microstructure of the silicate coating.

The change in particle size and surface area of the samples due to heating were determined using atomic force microscopy (AFM) analysis and BET surface area analysis respectively. Roggendorf et al. ${ }^{11}$ have shown that heating the silicates reduces its particle size. As the drying temperature increases, the particle size decreases to the range of 1-5 nm. AFM pictures of samples (not shown here) dried at 40 and $75^{\circ} \mathrm{C}$ show that the particle size of the coating decreases from 464 to $85.3 \mathrm{~nm}$. This decrease in the particle size results in a less porous and more compact coating and translates to better corrosion resistance. Figure 4 gives the particle size along with the surface area of the coating as a function of drying temperature. The particle size decreases from $0.5 \mu \mathrm{m}$ to the order of $5 \mathrm{~nm}$ when the drying temperature is changed from 40 to $200^{\circ} \mathrm{C}$. The BET

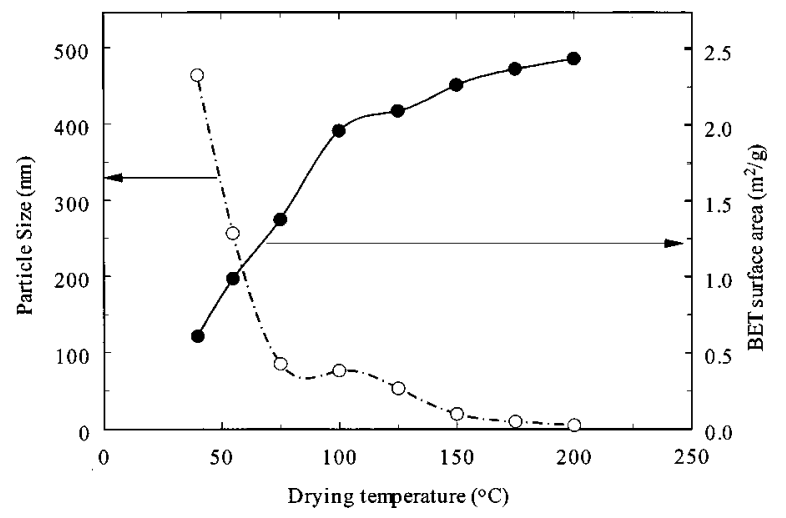

Figure 4. Variation in particle size and surface area of the coatings as a function of drying temperature as determined by AFM and BET analysis.

surface area of the coatings increases with increase in drying temperature. This result serves as a confirmation for the decrease in the particle size of the coatings. These results, coupled with the corrosion resistance data, indicate that increased drying temperature results in better corrosion stability.

Comparison to chrome salt passivates.-Because the focus of this paper was to develop not only an environmentally friendly process but also to replace chromium conversion coatings, a comparison is made between different coatings. Commercially available yellow chromate and white chromate coated galvanized steel were subjected to corrosion testing in $0.5 \mathrm{M} \mathrm{Na}_{2} \mathrm{SO}_{4}$ (pH 4). The comparison between the various coatings is shown in Fig. 5. The base $\mathrm{Zn}$ coatings give a resistance in the range of $250 \Omega \mathrm{cm}^{2}$. The chromate coatings typically gave a resistance in the range 800-1400 $\Omega \mathrm{cm}^{2}$. When compared with these coatings, the silicate coatings provide a much better performance with at least one order of magnitude higher resistance than the chromate conversion coatings even after a week of corrosion testing. All these results show that the silicate deposition can be a potential candidate to replace the chromate conversion coatings.

\section{Conclusions}

A novel nonchrome method for protecting zinc surfaces based on the deposition of silicates from sodium silicate solutions has been developed. It was found that inclusion of a post-treatment heating procedure in the process increases the resistances of the coatings significantly. The various deposition parameters have been optimized based on the corrosion characteristics of the coatings. The technique developed here shows promise as an alternative to chrome passivation for corrosion protection of metals.

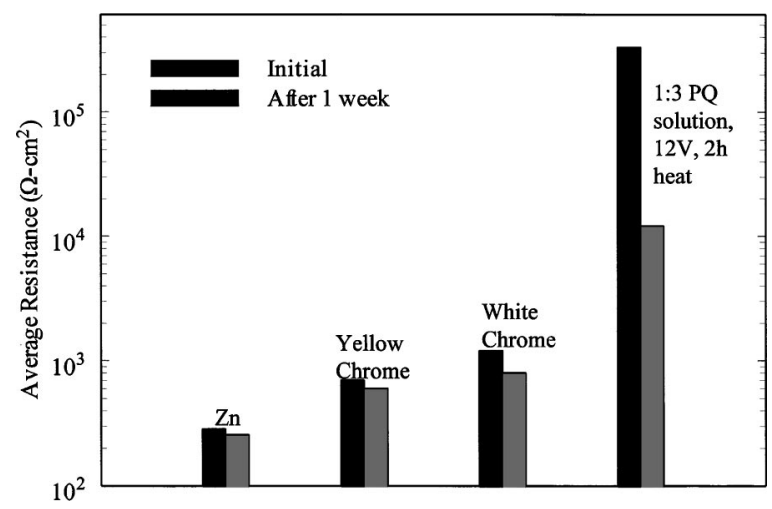

Figure 5. Comparison of corrosion resistance of various coatings used for protecting zinc. 
The University of South Carolina assisted in meeting the publication costs of this article.

\section{References}

1. X. Cheng, Z. Wang, and Y. Yan, Electrochem. Solid-State Lett., 4, B23 (2001).

2. T. Jesionowski, Colloids Surf., B, 190, 153 (2001).

3. E. A. Speers and J. R. Cahoon, J. Electrochem. Soc., 145, 1812 (1998).

4. M. Chigane, M. Ishikawa, and M. Izaki, Electrochem. Solid-State Lett., 5, D9 (2002).

5. T. L. Barr, Modern ESCA-The Principles and Practice of X-Ray Photoelectron Spectrocopy, CRC Press, Boca Raton, FL (1994).

6. H. He, T. L. Barr, and J. Klinowski, J. Phys. Chem., 98, 8124 (1994).
7. L. Sziraki, A. Cziraki, Z. Vertesy, L. Kiss, V. Ivanova, G. Raichevski, S. Vitkova, and Ts. Marinova, J. Appl. Electrochem., 29, 927 (1999).

8. J. L. Bass and G. L. Turner, J. Phys. Chem. B, 101, 10638 (1997).

9. M. Pourbaix, Atlas of Electrochemical Equilibria in Aqueous Solutions, Section 15.1, Pergamon Press, New York (1966).

10. R. K. Iler, The Chemistry of Silica: Solubility, Polymerization, Colloid and Surface Properties, and Biochemistry, John Wiley \& Sons, New York (1979).

11. H. Roggendorf, D. Boschel, and J. Trempler, J. Non-Cryst. Solids, 293-295, 752 (2001).

12. A. Krysztafkiewicz, R. Werner, L. K. Lipska, and T. Jesionowski, Colloids Surf., A, 182, 65 (2001) 